\title{
Relações de apego no contexto da institucionalização na infância e da adoção tardia
}

\author{
Attachment in the context of institutionalization in the infancy and in late adoption
}

Lilia lêda Chaves Cavalcante ${ }^{[a]}$, Celina Maria Colino Magalhãeses ${ }^{[b]}$

\footnotetext{
${ }^{[a]}$ Docente do Programa de Pós-Graduação em Teoria e Pesquisa do Comportamento da Universidade Federal do Pará (UFPA), professora adjunta da Faculdade de Serviço Social, Belém, PA - Brasil, e-mail: liliaccavalcante@gmail.com

${ }^{[b]}$ Docente do Programa de Pós-Graduação em Teoria e Pesquisa do Comportamento da Universidade Federal do Pará (UFPA), bolsista de produtividade do CNPq, Belém, PA - Brasil, e-mail: celina.magalhaes@ pesquisador.cnpq.br

Recebido: 05/04/2011 Received: 04/05/2011

Aprovado: 14/07/2011 Approved: 07/14/2011
}

\begin{abstract}
Resumo
Estudos apresentam evidências de que são vários os fatores que podem influenciar a qualidade do apego entre pais e filhos adotivos, em particular quando isso envolve crianças com histórico de longa permanência em abrigos e instituições similares. 0 tema tem sido ainda pouco explorado pela literatura científica, considerando que são raros os estudos que propõem a discussão da formação do apego nesse contexto específico. Entre as realizadas nas últimas décadas, está a sugestão de que são importantes os efeitos para o desenvolvimento do tempo que a criança passou no convívio com figuras de referência na família de origem e em instituições de acolhimento infantil antes de ser adotada. Desse modo, estudos têm apresentado um conjunto de fatores que podem favorecer ou inibir a formação do apego nessas relações, mas poucos destacam a disponibilidade da criança adotada tardiamente, assim como de seus novos cuidadores, para essa forma de vinculação. Este artigo cumpre assim com o propósito de apresentar referências bibliográficas que ilustram a produção sobre o tema e oferecem subsídios para esse debate na contemporaneidade.
\end{abstract}

Palavras-chave: Apego. Institucionalização na infância. Adoção tardia.

\section{Abstract}

Studies provide evidence that there are many factors that can influence the quality of attachment between parents and adopted children, particularly when it involves children with a history of long-stay in shelters and similar institutions. The theme has yet been little explored by the scientific literature, whereas there are rare studies that propose discussion about the formation of attachment on such specific context. Among the studies held in recent decades, there is a suggestion that, for a child, the effects of time she spent, before being adopted, in contact with important figures from the origin family and in children shelter institutions are important for the development for that child. Thus, studies have shown a set of factors that might promote or inhibit the formation of attachment in such relationships, but a few of them highlight the availability of a late-adopted child, as well as of her new caretakers for this form of binding. This way, this paper complies with the purpose of presenting references that illustrate the production on the issue and provide input to this debate in contemporary society.

Keywords: Attachment. Institutionalization in childhood. Late adoption. 


\section{Relações de apego na infância: Notas introdutórias}

Entre estudiosos do desenvolvimento humano, com maior ou menor ênfase, a infância tem sido apresentada como um período que engloba vários e complexos processos: crescimento orgânico e maturação neurológica, organização do pensamento e raciocínio, percepção e expressão da emoção, interação e relação social (Bowlby, 1997; Bronfenbrenner, 1996).

Nessa área do conhecimento, estudos teóricos e empíricos sobre desenvolvimento infantil têm privilegiado o que tem sido considerado como talvez a mais importante das propriedades humanas: a capacidade de construir vínculos e relações de apego.

Para Hrdy (2001), os humanos, assim como outras espécies animais, nascem biologicamente preparados para estabelecer e manter uma ligação emocional, forte e duradoura com a mãe ou qualquer outra figura de apego primário. As crianças já nascem com a necessidade de se apegar. Os seres humanos são, por assim dizer, nascidos para o apego. É o que podemos considerar como a dimensão biológica do vínculo. Das ligações primárias depende a sobrevivência do filhote humano, principalmente nos primeiros anos de vida, pois requer ajuda para ser alimentado, protegido do frio e calor excessivo, mantido próximo e a salvo de estranhos que ofereçam risco à sua segurança.

Assim, Bowlby (1997) compreende que entre os mamíferos, sobretudo os primatas, - incluindo os humanos -, o primeiro e mais contínuo dos vínculos é o estabelecido entre a mãe e seu filho pequeno, entre a criança e seu cuidador habitual, prolongando-se em geral da infância até a vida adulta. Nessas condições, entre os parceiros, existe o que pode ser definido, segundo o autor, como uma inclinação natural para manterem-se próximos um do outro. Nesse sentido, a vinculação se estabelece e se consolida pela proximidade, pela convivência contínua. A formação do vínculo é essencial e torna possível, na eventualidade da separação dos parceiros, disposição para recompor os laços afetivos que foram desfeitos. Por isso, argumenta que a separação entre pares vinculados não ocorre comumente sem resistências - o mais fraco agarra-se ao mais forte buscando proteção contra o elemento estranho, especialmente quando se trata da díade composta por mãe e filho.

Em que pese a existência de críticas à ênfase dada por essas formulações iniciais à base instintiva das ligações humanas, a compreensão da natureza do vínculo entre animais inspirou estudos semelhantes com humanos e que até hoje são referências importantes no meio científico, entre os quais se deve dar merecido destaque ao conjunto da obra de Mary Ainsworth, resultado de uma fecunda parceria com John Bowlby, a partir da década de 1950 (Bretherton, 1992).

Entre 1953 e 1967, Mary Ainsworth realizou estudos precursores sobre o apego entre mãe e filho. Primeiro com bebês na faixa etária de 1 a 24 meses, na África; depois, em Baltimore, nos EUA, com crianças que tinham entre 10 e 24 meses. 0 experimento, que ficou conhecido no mundo inteiro como Situação Estranha, procurou registrar comportamentos que promoviam a proximidade entre mãe e filho, constatando que os sinais emitidos pela criança eram dirigidos predominantemente à mãe. Após várias repetições do mesmo experimento, ficou claro que a maioria dos bebês, cerca de $60 \%$, brinca e explora o novo ambiente de maneira mais tranquila e ativa, quando na presença da mãe. Contudo, os bebês reagem de maneira diferente às circunstâncias criadas pelo experimento - o afastamento da mãe e a proximidade do estranho. Em geral, demonstram satisfação e alívio diante da presença da mãe, mas, por vezes, manifestam raiva ou indiferença ao reencontrá-la após o período de separação.

Os resultados obtidos permitiram categorizar diferentes tipos ou padrões de apego quanto ao grau de confiança e segurança presente na relação entre mãe e filho. 0 apego foi definido basicamente como seguro ou inseguro, embora existam outras variações de qualidade - indiferente, ambivalente ou desorganizado. No apego seguro, o mais comum nas situações pesquisadas até hoje, a criança busca, de forma moderada, conforto e contato físico com a mãe, mas especialmente ao reencontrá-la após um período de afastamento. A criança demonstra claramente que prefere a mãe ao estranho. No apego inseguro-esquivo, a criança evita o contato com a mãe, principalmente quando se reúne a ela após a separação. Não resiste às tentativas da mãe em fazer contato, mas também não busca a proximidade. A criança trata de forma semelhante a mãe e o estranho. No apego inseguro-desorganizado, a criança apresenta comportamento contraditório, confuso ou apreensivo em relação ao contato com a mãe. Quando a reencontra após a separação, pode aceitar o conforto oferecido por ela e, ao mesmo tempo, evitar manter qualquer contato visual. 
Os efeitos da separação ou perda da figura de apego investigados por Bowlby (1995) e Ainsworth (1983), contribuíram para deixar claro o valor das figuras primárias de apego para o desenvolvimento humano, além de discutir questões que dizem respeito à situação de crianças encaminhadas a instituições precocemente e tempos depois acolhidas em lares adotivos. Em todo o, mundo essa é uma realidade secular e é possível encontrar ainda hoje milhares de crianças que passam os primeiros dias, meses e até anos de sua infância em instituições de abrigo, sob a responsabilidade de profissionais que se revezam na tarefa de lhes prover cuidados substitutos, que funcionam como uma alternativa à convivência em família.

Por essas e outras razões, considera-se que os limites e as possibilidades para a construção de novos vínculos afetivos e a formação do apego entre pais e filhos adotivos devem ser discutidos à luz da compreensão teórica dos efeitos da institucionalização prolongada na chamada primeira infância para a criança, sob pena de se subtrair dos fundamentos dessa análise aspectos outros que são decisivos face às particularidades de sua trajetória desenvolvimental.

\section{Institucionalização na infância e suas implicações para a formação do apego}

No Brasil (Ipea, 2004), assim como em várias regiões do mundo (Unicef, 2010), a separação involuntária dos pais ou a exposição à violência, à doença, ao abuso e à exploração, dentro e fora do lar, são situações frequentes e servem como justificativa para a longa permanência de crianças em instituições abertas ou fechadas, a exemplo dos abrigos, orfanatos, internatos, hospitais e unidades psiquiátricas.

De acordo com Roy, Rutter e Pickles (2000), a despeito do relativo consenso entre os especialistas de que a privação do cuidado parental nos primeiros anos de vida pode oferecer riscos ao desenvolvimento infantil, observa-se que as sociedades em geral ainda reforçam a ideia de que a colocação da criança em instituições de abrigo pode ser a única - e, por vezes, a melhor - alternativa em países atingidos por guerras, epidemias, catástrofes naturais, níveis extremos de pobreza e precariedade das redes de apoio social.
Entre os pesquisadores que se destacam no trato científico dessa questão, existe relativo consenso em torno da ideia de que, nos primeiros anos de vida, são graves as sequelas físicas, cognitivas, afetivas e sociais derivadas do tempo passado em instituições asilares, uma vez que a criança é afastada do seu ambiente familiar e passa a conviver com pessoas e situações estranhas, o que pode resultar em intensas manifestações emocionais como angústia e medo. Se o tempo passado longe de casa for demasiadamente longo, a possibilidade das sequelas decorrentes dessa experiência serem mais graves e persistentes tende a ser ain da maior, como mostram observações clínicas e pesquisas longitudinais que acompanharam a colocação de crianças em instituições, e depois, a sua convivência em lares adotivos.

Alguns desses estudos foram realizados há mais de meio século, mas permanecem atuais quando se consideram as contribuições apresentadas ao debate do tema em pauta. Outros, mais recentes, relativizam a pertinência dos estudos precursores para a compreensão do fenômeno na contemporaneidade, difundindo a ideia de que toda e qualquer sequela pode ser prevenida ou minimizada a partir de fatores que protegem e promovem o desenvolvimento da criança durante a sua prolongada permanência em instituições, mas principalmente após essa experiência, em que as oportunidades de vinculação e apego com novos cuidadores em um lar adotivo podem ser decisivas para a qualidade do desenvolvimento esperado.

Nesse sentido, estudos divulgados a partir de meados do século passado, como os trabalhos de Bowlby [1976] 1995, ([1979] 1997), Bronfenbrenner ([1994] 1996), Freud e Burlingham (1960), Provence e Lipton (1962), Spitz ([1965] 1998), Tizard e Hodges (1978), guardam importância histórica na medida em que impulsionaram o debate sobre os efeitos do cuidado institucional precoce e prolongado para a aquisição de importantes competências cognitivas, onde se ressalta o seu processo de desenvolvimento sócio-emocional.

Entre os precursores do debate sobre esse tema está Spitz ([1965] 1998), que, na primeira metade do século XX, demonstrou que situações de privação afetiva, total ou parcial, levam muitas crianças cuidadas em instituições a manifestar uma espécie de síndrome, um conjunto de sintomas de natureza física e psíquica que afetam o desenvolvimento da criança. 
Nesses termos, a chamada Depressão Nosológica está relacionada à presença de um quadro clínico que envolve, inicialmente, choro insistente, perda progressiva de peso, evoluindo para a recusa do contato com outras pessoas, perturbações no ritmo do sono, maior vulnerabilidade a doenças infecto-contagiosas graves, e, em casos extremos, possibilidade de poder haver manifestação de rigidez facial e outros problemas neurológicos.

Freud e Burlingham (1960) também realizaram estudo em berçários que acolhiam crianças sem lar e privadas do convívio com os pais. As autoras dedicaram especial atenção ao estudo dos efeitos do stress gerado pela privação dos cuidados maternos para o desenvolvimento dos chamados Órfãos da Guerra, analisando com propriedade a extensão dessas sequelas psicológicas e os recursos oferecidos pela terapia psicanalítica infantil para sua reparação. Na discussão do conteúdo de suas observações clínicas deixaram claro a pertinência dos achados de outros estudos psicanalíticos sobre a traumática experiência da institucionalização prolongada e suas implicações para a dimensão afetiva das relações da criança com seus cuidadores e pares, realizados mais ou menos no mesmo período.

É o caso do trabalho publicado por James Robertson, em 1948, que realizou avaliação diagnóstica sobre a situação da saúde mental de crianças institucionalizadas, apoiado pela Organização Mundial da Saúde. 0 estudo envolveu crianças de ambos os sexos, com 2 e 3 anos, que tinham em comum o fato de terem sido cuidadas fora do lar por um determinado tempo. Ele as observou antes, durante e depois do retorno ao convívio com a família. As crianças que participaram da pesquisa permaneceram durante semanas ou até meses em ambientes institucionais, como hospitais ou entidades de assistência social, sempre em regime de internação e com o convívio de profissionais que se revezavam em seus cuidados diários, mas sem a presença de uma mãe-substituta estável.

Na esteira dessa polêmica, em 1952, John Bowlby publicou obra que apresenta e discute questões relacionadas à privação do contato físico entre mãe e filho e as implicações afetivas dessa separação nos primeiros anos da infância, lançando luzes sobre a investigação de situações nas quais a criança recebe os cuidados primários em ambiente institucional, mas não consegue estabelecer trocas afetivas e contínuas com os cuidadores substitutos, procurando alertar para os prejuízos deixados por essa experiência ao desenvolvimento infantil.

Em que pese críticas sofridas ao longo do tempo, o conjunto dos trabalhos citados nos parágrafos anteriores serve ainda como referência para estudos mais recentes sobre a condição psicossocial da criança institucionalizada, mas principalmente quanto aos limites e às possibilidades do desenvolvimento humano em contextos marcados pela privação material e afetiva.

Entre os representantes de uma perspectiva ecológica acerca dos efeitos da longa permanência em instituições para a condição psicossocial da criança, Bronfenbrenner ([1994] 1996) resgata a importância dos precurssores nesse debate. Traz novas e importantes contribuições ao argumentar que o potencial desenvolvimental das crianças cuidadas em instituições aumenta na razão direta em que o meio físico e social favorece a assimilação de padrões de interação recíproca com seus pares e cuidadores que desempenham papel parental, assim como abre espaço para a construção de relacionamentos diádicos primários cada vez mais complexos, como devem ser definidas as relações de apego.

Na perspectiva da ecologia do desenvolvimento, Bronfenbrenner (1996) considera que a família e as instiuições infantis constituem-se contextos primários, abrangentes e complexos, no qual a criança realiza atividades, constrói relações e desempenha papéis que podem beneficiar em maior ou menor medida o curso do desenvolvimento. Isso significa dizer que a criança não interrompe a sua trajetória de desenvolvimento a partir do momento em que deixa a convivência com a família de origem e passa a viver sob os cuidados de uma instituição. Ao contrário, como contexto ecológico abrangente, a instituição oportuniza à criança o envolvimento em múltiplas atividades, papéis e relações que, em maior ou menor medida, exercem influência sobre a sua trajetória desenvolvimental como um todo.

Por seu turno, Zeanah et al. (2003) chamam atenção para o fato de que viver e crescer em uma instituição do tipo asilar implica em acumular experiências que têm o poder de afetar o desenvolvimento global da criança, principalmente quando ocorrem nos primeiros 36 meses de vida. 0 período que se estende da concepção até a idade de três anos é particularmente decisivo para o desenvolvimento, uma vez que são processadas rápidas, complexas e profundas mudanças na formação da 
mente da criança. É precisamente nessa fase da vida que a criança passa de um quadro de completa dependência dos cuidadores primários em razão de limitações de ordem motora, verbal e cognitiva, a uma refinada capacidade de entendimento e participação ativa em situações regidas por regras sociais.

Entende-se, assim, que o afastamento da família e a permanência da criança em instituição que ofereça pouco estímulo ao funcionamento das estruturas cerebrais, são experiências que podem limitar os notáveis avanços desenvolvimentais esperados nessa fase da vida. Com base nos achados de Zeanah et al. (2003), é possível notar que sequelas derivadas de um longo e precoce período de privação costumam ser mais graves e persistentes se, e somente se, o ambiente institucional for limitado em sua capacidade de gerar estímulos à criança que está em uma fase da vida particularmente sensível ao aprendizado social e à constituição de um padrão afetivo.

Sobre a questão, Dozier, Stovall, Albus e Bates (2001) defendem que a longa permanência em instituições de acolhimento pode resultar em riscos ao desenvolvimento global da criança, e, por isso mesmo, deve ser evitada. Contudo, os riscos implicados nessa experiência assumem contornos mais preocupantes apenas quando limitam a capacidade da criança de criar e manter relações estáveis e duradouras, seja com profissionais responsáveis por sua rotina de cuidados, seja com seus pares no intenso convívio no cotidiano da instituição.

Na presente década, pesquisas começam a dar um passo à frente na compreensão da complexidade que envolve os processos de institucionalização e seus efeitos imediatos e em longo prazo para o desenvolvimento humano. Estudos comparam hoje diferentes aspectos do desenvolvimento de crianças que, em seus primeiros meses ou anos de vida, foram cuidadas em instituições e, depois, em lares adotivos. Em sua maioria, são estudos comparativos e longitudinais que têm em comum o fato de trabalharem com amostras de crianças com histórico de institucionalização precoce e prolongada, como resgatam Sigal, Perry, Christopher, Rossignol e Ouimet (2003) e Zeanah, Smyke, Koga e Carlson (2005) a partir de minuciosa revisão da literatura disponível sobre o tema.

Assim como os precursores na discussão desse tema, pesquisas recentes evidenciam ora a presença de déficits duradouros no funcionamento psicológico da criança institucionalizada, ora os efeitos perceptíveis da privação afetiva para a segunda geração. Na trajetória do desenvolvimento da criança com histórico de institucionalização prolongada e adoção tardia (após os dois ou três anos de idade), estudos mostram que tais sequelas estão geralmente associadas à privação afetiva associada ao cuidado material e emocionalmente negligente dedicado à criança no tempo em que conviveu com a sua família de origem e/ou na instituição onde passou parte significativa da infância. De maneira geral, estudos atuais confirmam a tese já existente de que a privação afetiva traz, em alguma medida, prejuízos ao desenvolvimento físico, cognitivo e emocional, contudo definem hoje a hipótese de que a extensão desses efeitos dependerá dos riscos potenciais da exposição da criança a um padrão de acolhimento e cuidado institucional, ao mesmo tempo, precoce, exclusivo e prolongado.

Os achados e hipóteses de estudos realizados nos dez últimos anos assumem, portanto, clara importância para a discussão proposta neste artigo, por permitirem a compreensão de como e por que os processos de institucionalização prolongada e adoção tardia estão comumente imbricados e exercem influência na capacidade da criança sob essas condições desenvolvimentais, construir e manter relações de apego ao longo da infância e nos anos seguintes.

Entre as pesquisas que contribuem para esse debate, faz-se referência especial aos estudos que avaliam o curso do desenvolvimento de crianças adotadas a partir de instituições sediadas no Leste Europeu, Rússia e outros países onde muitas famílias enfrentam adversidades sociais graves, compondo uma população que apresenta um leque de problemas relacionados, ora à privação do cuidado parental, ora às características hostis que marcam a vida institucional.

Em estudo longitudinal realizado por 0'Connor, Rutter, Beckett, Keaveney e Kreppner (2000), em conjunto com pesquisadores do English Romanian Adoptees Study Team (ERA), avaliam a extensão dos efeitos da privação severa sobre o desenvolvimento da criança nos primeiros anos de vida. Nesse estudo, em particular, a equipe de pesquisadores trabalhou com três amostras de crianças adotadas por famílias residentes no Reino Unido, entre 1990 e 1992. No primeiro, grupo selecionaram 165 crianças (de um total de 324) com histórico de privação 
severa de ordem material e emocional. Após rigorosa avaliação dos pesquisadores, a amostra final foi composta por 111 crianças adotadas de 0 a 24 meses de idade, sendo $51 \%$ dos participantes do sexo masculino. No segundo grupo, estavam 48 crianças romenas também adotadas por famílias do Reino Unido, na faixa etária de 24 a 42 meses, com predomínio do sexo feminino (65\%). 0 terceiro grupo era constituído por um contingente de 52 crianças, oriundas do Reino Unido, que não possuíam em seu histórico experiência de privação severa anterior.

Independente da idade em que foram adotadas as crianças participantes da pesquisa, a maioria foi encaminhada à instituição nas primeiras semanas de vida, apenas um pequeno número convivera antes em ambiente familiar. Em geral, as crianças pesquisadas estavam severamente desnutridas e apresentavam as marcas do cuidado negligente recebido em instituições romenas.

Os procedimentos da pesquisa que objetivavam submeter à avaliação o desenvolvimento global das crianças e comparar resultados apresentados pelas amostras, foram os seguintes: 1) Medidas Antropomórficas (registra peso, altura e circunferência da cabeça); 2) Índice Global Cognitivo (analisa aspectos como percepção, memória, expressão verbal e quantitativa por meio da Escala de McCarthy, 1972 e Merril-Palmer, ANO); 3) Questionário Revisado de Denver (recupera relatos parentais quanto a alterações nos comportamentos sociais, linguagem, psicomotricidade fina e grossa). Do ponto de vista qualitativo, outras medidas foram ainda utilizadas pelos pesquisadores: percepção dos pais adotivos quanto à manifestação de problemas comportamentais na fase pré-escolar, a frequência às aulas e o tipo de instituição de ensino que a criança passou a frequentar no Reino Unido (pública ou privada).

O experimento revelou avanços na evolução dos dados antropomórficos e na aquisição de habilidades cognitivas entre as crianças que compunham os três grupos de adotados. Foram considerados dados da avaliação feita no momento em que ingressaram no Reino Unido e os escores obtidos em nova aferição feita aos 4 e 6 anos a partir de uma bateria de testes e relatos parentais. Entretanto, quando os pesquisadores observaram o desempenho das crianças em todas as medidas de avaliação do desenvolvimento, as que foram colocadas tardiamente em lar adotivo, ou seja, após os dois anos de idade, apresentaram sempre os escores mais baixos. $\mathrm{Na}$ Escala de Denver, por exemplo, 18\% das crianças expostas há mais tempo aos riscos próprios do cuidado institucional, negligente e exclusivo, alcançaram pontuação inferior a 70 .

Os resultados indicam que parte das crianças expostas à privação severa no início da vida apresentou déficits cognitivos mais elevados quando comparadas as que não haviam tido essa experiência, ainda que os pesquisadores tenham notado expressiva variabilidade em termos das diferenças individuais nos escores referentes à avaliação realizada aos de seis anos de idade, fato que talvez esteja associado aos benefícios derivados do cuidado no pré-natal e influências genéticas.

Em que pese reconhecerem a importância desses achados, para O'Connor, et al. (2000) e pesquisadores do ERA, não seria possível afirmar de forma conclusiva que a deterioração e os avanços no desenvolvimento físico e cognitivo das crianças avaliadas guardam correlação significativa com a duração da privação (se foi longo o tempo de permanência na instituição ou não) ou ainda o tempo de convivência em família substituta (se a adoção ocorreu tardiamente ou não). Para esses autores, assim como para muitos dos por eles citados, outras variáveis precisam ser consideradas para explicar de maneira consistente alterações no curso do desenvolvimento de crianças com histórico de privação severa e cuidado institucional prolongado.

0 trabalho de Ames (1997) amplia o leque dessas análises ao sinalizar os elementos que precisam ser considerados na avaliação das trajetórias desenvolvimentais dessas e outras tantas crianças adotadas. Para a autora, que estudou detidamente o processo de adaptação de crianças romenas adotadas por famílias em países de cultura anglo-saxônica, entre 1990 e 1991, entre outros fatores que podem ter contribuído para atenuar os efeitos da longa espera por uma família em instituições asilares, o contato regular com brinquedos e atividades lúdicas deve ter sido decisivo para a melhoria da qualidade dos cuidados recebidos no período.

Estudos têm mostrado que a brincadeira facilita a elaboração pela criança de sentimentos e emoções intensos, tais como o medo, a raiva e a tristeza, permitindo alargar as fronteiras do autoconhecimento e identificar limites e recursos próprios para lidar com essas manifestações emocionais. Por meio da brincadeira, a criança sente-se a vontade para expressar 
verbalmente aspectos do seu universo afetivo, compreendendo comportamentos que traduzem seu grau, a sua angústia diante de privações de toda ordem, como também os mecanismos de superação que a tornam tão resiliente quanto possível face às condições adversas presentes em seu ambiente imediato. Sob a ótica de Ames (1997), a convivência em instituições que oportunizavam experiências lúdicas que favorecem sensações de prazer, conforto e segurança, aproximando afetivamente adultos e crianças, provavelmente aumentou a chance da prevenção de graves sequelas cognitivas e emocionais na população de crianças estudada por ela e outros autores.

Esses e outros trabalhos de autores como O'Connor et al. (2000) e Ames (1997), definem, neste artigo, as bases para uma compreensão alargada da influência que podem ter experiências anteriores de privação severa na adaptação da criança ao lar adotivo, onde se inclui a sua disponibilidade para a construção de novos vínculos afetivos, assim como os desafios postos por esse processo em termos da superação por pais e filhos dos efeitos gerados pela prolongada exposição à pobreza e a convivência em ambientes com pouca oferta de estímulos físicos e sociais.

Percebe-se, assim, que a discussão sobre os efeitos da privação severa para a adaptação posterior da criança às condições apresentadas pelo lar adotivo deve envolver outras questões importantes: a validade da hipótese que prevê a existência de períodos críticos do desenvolvimento que favorecem a aquisição de certas habilidades cognitivas e sociais; os limites da resiliência infantil em contextos marcados por condições material e emocionalmente adversas; a existência de mecanismos pelos quais experiências precoces podem se constituir em fatores de risco para o amadurecimento psicológico da criança.

0 pioneirismo desses primeiros trabalhos teve certamente o mérito de levantar questões que permanecem atuais entre pesquisadores contemporâneos. Entre tantas, destaca-se: Quais as implicações da interrupção dos cuidados em família e a longa permanência em ambiente institucional para a formação de um padrão de apego emocionalmente seguro a partir do momento em que a criança passa a conviver em lares adotivos?

Talvez o primeiro passo para se buscar possíveis respostas a essa e outras questões esteja no reconhecimento de que a importância das ligações primárias para o desenvolvimento e a atualidade do debate acerca dos efeitos da privação afetiva que está associada a um padrão de cuidado institucional, prolongado e exclusivo, na fase inicial da vida. Essas são, portanto, questões inexoravelmente ligadas entre si.

\section{0 apego entre pais e filhos em situações de adoção tardia}

Estudos têm mostrado que bebês adotados que, desde os primeiros meses de vida, receberam os cuidados primários por parte de pessoas com as quais não mantêm vínculos familiares, provavelmente têm diante de si o desafio da formação do apego e do laço afetivo que os unirá aos seus novos cuidadores. Em geral, quando são deixados em instituições por muito tempo, por vezes desde o nascimento, os bebês adotados experimentaram antes condições reconhecidas como emocionalmente problemáticas, em particular a interrupção nas relações estabelecidas com seus cuidadores primários na família ou em ambiente institucional.

Especificamente sobre essa questão, Zeanah, Smyke, Koga e Carlson (2005) realizaram estudo que examinou a qualidade do apego em dois grupos de crianças que residiam em Bucharest, na Romênia. 0 primeiro era formado por 95 crianças cuidadas exclusivamente em ambiente institucional. 0 outro grupo reunia 50 crianças que nunca haviam sido institucionalizadas, tendo convivido em ambiente familiar desde o nascimento. As crianças selecionadas eram de ambos os sexos e tinham idades entre 12 e 31 meses. Ao longo da duração da pesquisa, foram realizadas entrevistas estruturadas com os cuidadores primários dessas crianças e procedimentos do experimento elaborado por Ainsworth, Bell e Donelda (1983), mundialmente conhecido como "Situação Estranha".

Nesse estudo, na ausência dos pais, os pesquisadores procuraram identificar quem eram os cuidadores habituais por quem as crianças manifestavam clara preferência. Os resultados demonstraram que as crianças que recebiam os cuidados primários, exclusivamente em instituições assistenciais, compunham o grupo que apresentou maior dificuldade para se vincular aos seus cuidadores e apresentar comportamentos associados à formação e organização do apego. Zeanah et al. (2005) verificaram ainda 
que apenas $22 \%$ das crianças que se encontravam institucionalizadas por ocasião do experimento desenvolveram estratégias de apego em situações de interação com cuidadores por quem demonstravam algum nível de proximidade ou preferência. Já entre as crianças que eram cuidadas exclusivamente em ambiente familiar, esse percentual foi mais elevado, aproximadamente 78\% desenvolveram estratégias para a formação do apego. As crianças que conviviam com seus pais apresentaram diferenças significativas na quantidade e na qualidade do contato com seus cuidadores, o que deve ter sido decisivo do ponto de vista emocional para a formação do padrão de apego seguro em índices mais elevados do que os encontrados no grupo que recebia atenção somente de cuidadores profissionais.

Igualmente, para Dozier, Stovall, Albus e Bates (2001), existem hoje evidências empíricas suficientes de que essas experiências prévias podem, em alguma medida, diminuir as chances dos filhos adotivos construírem relações de confiança com seus novos pais e cuidadores, o que não significa exatamente eliminá-las. Sobre a polêmica que gira em torno desse debate, a literatura sobre o tema mostra que, mesmo em condições consideradas pouco favoráveis do ponto de vista social e emocional à formação do vínculo e à manifestação do apego, crianças adotadas conseguem organizar seu comportamento de apego. Isso em razão da presença de variáveis fortemente relacionadas ao processo de vinculação, em que tem sido destacada pelos autores a disponibilidade de seus novos cuidadores para a vivência desse tipo de experiência.

Dozier et al. (2001) consideram que, ainda que existam fortes evidências de que a formação do apego esteja relacionado de uma ou de outra forma às sequelas deixadas pelo longo tempo de privação afetiva ao qual a criança esteve exposta antes e durante a sua permanência em instituições asilares, poucos são os estudos dedicados especificamente ao exame da natureza do apego formado por crianças adotadas com seus novos cuidadores. De acordo com os autores, de maneira geral, esse é um tema ainda pouco explorado na literatura científica, quando se toma como referência a quantidade de vezes em que crianças de diversas nacionalidades são adotadas em seu próprio país ou por outros de culturas distantes. Graças a isso, as publicações destinadas à questão da questão acabam por tomar como referência a experiência afetiva de díades intactas, reconhecendo-as como úteis na sugestão de hipóteses teóricas que podem esclarecer como se dão as relações de apego entre pais e filhos adotivos com histórico de institucionalização nos primeiros anos da infância.

Em qualquer contexto relacional, sabe-se hoje, a questão da qualidade do apego é considerada muito importante pelos pesquisadores da área da Psicologia e afins, porque reflete a qualidade da relação da criança com quem dela cuida no cotidiano, além de que comumente está associada à função interpessoal que ela irá desenvolver posteriormente. Em revisão à literatura que discute o tema, Dozier et al. (2001) verificaram que as crianças que desenvolvem apego seguro com seus cuidadores primários mostram-se mais competentes na habilidade de resolver problemas posteriores, mais independentes e confiantes com professores e outros pré-escolares, mais dispostas aos comportamentos interativos com seus pares na idade escolar do que outras que vivem em ambientes pobres em estímulos para a interação social e a vinculação afetiva. Inversamente, concluíram que crianças com experiência de apego desorganizado na relação com seus cuidadores primários e pessoas de referência apresentaram mais frequentemente comportamento agressivo com seus pares e sintomatologia dissociativa evidenciada no decorrer da infância.

Para tornar mais consistentes e válidos os achados científicos relativos às experiências de apego vividas em diferentes contextos relacionais, Dozier et al. (2001) afirmam que tem sido investigada a qualidade do apego de crianças com cuidadores que foram definidos pelos pesquisadores como não biológicos, e que foram, ora adotadas logo após o seu nascimento, ora mantidas por longo período em instituições como abrigos e orfanatos. Entende-se que essas investigações têm sido úteis por sugerirem, no mínimo, o nível de complexidade que envolve a formação de novas relações de apego em substituição as que eram antes mantidas pela criança em períodos anteriores de sua vida.

Com base em dados que revelam as condições extremamente desfavoráveis ao cuidado infantil em orfanatos na Romênia, Dozier et al. (2001) chamam atenção para a experiência de crianças que cresceram nesse contexto específico e que depois passaram a ser estudadas a partir da sua inserção em famílias substitutas no Reino Unido, Canadá e Estados Unidos. Entre outros resultados, constatou que 66\% 
das crianças adotadas por volta dos quatro meses de idade desenvolveram apego seguro com seus pais adotivos. Esses autores consideram que essa realidade não é significativamente diferente daquela que foi encontrada em um grupo de crianças não adotadas em condições semelhantes por Chisholm (1998), que observou que 58\% delas desenvolveram apego seguro. No entanto, a situação começa a mudar quando se considera a amostra de crianças que haviam convivido em ambientes institucionais por pelo menos oito meses. Nessas circunstâncias, o pesquisador verificou que somente $37 \%$ desenvolveram apego seguro na relação com seus pais adotivos. Igualmente, apurou que essas crianças que permaneceram sob a guarda da instituição por um período considerado demasiadamente longo apresentavam índices mais altos de apego desorganizado e comportamento indiscriminadamente amigável com estranhos.

Na interpretação desses e de outros achados que apontam na mesma direção, Dozier et al. (2001) ressaltam que algumas ponderações precisam ser feitas para que não se tirem conclusões precipitadas e distorcidas sobre a questão. A primeira e principal ponderação a ser feita diz respeito à inadequação do cuidado ofertado às crianças romenas ao longo do tempo passado continuamente em orfanatos e similares, qualificado por Cicchetti e Barnett (1991) como pouco estável e personalizado, tendo sido a maioria das crianças que passaram pela instituição, negligenciada emocionalmente ao extremo. Por isso, advertem eles, esta entre outras descobertas, sugere muitas possibilidades de investigação do apego de filhos adotivos a seus novos cuidadores, mas especialmente ressalta a importância de se olhar para trás e reconhecer as condições em que eram cuidadas as crianças adotadas em instituições e o tempo em que estiveram expostas aos efeitos prejudiciais da privação afetiva. Entretanto, como traço comum entre tais experiências, fica a certeza de que é necessário olhar também para frente e analisar as condições reais e as oportunidades de vinculação efetivamente colocadas pela convivência em um lar adotivo, com seus novos cuidadores, como analisam Dozier et al. (2001). De acordo com esses autores, após um período de ajuste e consolidação, os filhos adotivos tendem a organizar seu comportamento de apego em torno da disponibilidade de seus novos cuidadores, entre outras condições contextuais apresentadas. Nesse contexto, chamam atenção para a hipótese de que, se são potentes os efeitos das experiências anteriores dos filhos adotivos no que diz respeito à qualidade do acolhimento institucional e à interrupção desse cuidado nos primeiros anos da infância, então, pode ser que as características dos pais adotivos e/ou dos novos cuidadores sejam em razão disso completa ou parcialmente neutralizadas. É como se as sequelas deixadas por um período da vida marcado por perdas afetivas subsequentes não conseguissem ser atenuadas e/ou reparadas completamente em razão das novas experiências de vinculação colocadas pela adoção.

Contudo, outros aspectos precisam ser adicionados e investigados no trato da questão. As associações entre as variáveis de interesse primário (por exemplo, estado da mente da mãe adotiva e apego da criança) e as variáveis de interesse secundário (idade da mãe adotiva, receitas financeiras, correspondência racial) foram pouco exploradas no estudo realizado por Dozier et al. (2001), indicando que os resultados por esse tipo de exame são ainda inconclusivos. Não é a toa que nesses estudos há constantemente a indicação da necessidade de análises subsequentes que possam captar a complexidade que envolve a pesquisa desse tipo de evento comportamental e desenvolvimental.

Desse modo, conforme salientam Dozier et al. (2001), considera-se que a idade e o estado civil da mãe adotiva, a condição sócio-econômica da família adotiva, o número de filhos adotivos na família substituta, a causa do encaminhamento da criança à instituição e ao lar adotivo, o número de colocações anteriores e a correspondência racial entre a mãe e o filho adotivo, são variáveis que não foram significativamente relacionadas ao estado da mente da mãe adotiva e ao apego da criança, ou mesmo a ambos.

Em resumo, em acordo com Dozier et al. (2001), conclui-se que os resultados dos estudos que investigam as relações de apego no contexto da adoção tardia confirmam a força da propensão humana para vincular-se ao outro capaz de lhe oferecer proteção, como uma experiência que tem por isso valor de sobrevivência para essa espécie. Nesse sentido, é possível afirmar que essa disposição está presente na criança adotada, a despeito das experiências de cuidado inadequado às quais esteve entregue, quer na família de origem uma vez que apresenta geralmente múltiplas adversidades psicossociais (Beckett, et al. 2006), quer em instituições marcadas comumente pela convivência com muitos 
cuidadores substitutos, mas nenhum em condições de ter com ela um relacionamento exclusivo (Tizard \& Hodges, 1978). Em razão do exposto, pode-se afirmar que essa propulsão humana para o apego se faz sentir na criança adotada apesar de interrupções subsequentes na relação estabelecida por ela com figuras de referência a partir de formas de cuidado previamente experimentadas (Dozier et al. 2001).

Entretanto, é sempre interessante lembrar que, nos casos mais graves em que estão presentes formas precoces e prolongadas de privação afetiva, como as citadas neste artigo, estudos têm mostrado que, quanto menor for a idade da criança e o tempo passado em instituições asilares, maiores são as chances de conseguir desenvolver confiança e apego seguro na relação com seus novos cuidadores em um lar adotivo. Isso significa que todos os esforços pessoais, institucionais e familiares devem apontar em uma única direção: quando não for possível evitar a separação da criança de sua família de origem, tornar o tempo de permanência na instituição o mais breve possível e oferecer a ela estímulos sociais e afetivos capazes de ativar a disposição para manter-se próximo de seus cuidadores substitutos e com eles construir relações estáveis, prazerosas e de confiança.

Sob essas condições, entende-se que a adoção tardia pode oferecer à criança a oportunidade de continuar investindo na construção de relacionamentos sociais mais estáveis e vínculos afetivos mais duradouros, porém, agora, em um novo e definitivo ambiente familiar.

\section{Considerações finais}

Pelo exposto neste artigo, percebe-se ser muito difícil desenhar conclusões firmes a partir dos resultados apontados por estudos aqui citados. Tais estudos investigaram as experiências afetivas entre pais e filhos no contexto da adoção tardia, visto que muitos foram e continuam sendo realizados em sociedades e culturas nem sempre compatíveis com a realidade de países como o Brasil. Desde a promulgação do Estatuto da Criança e do Adolescente, de 1990, e a Lei Nacional da Adoção, de 2009 (Unicef, 2010), a sociedade brasileira vem acumulando avanços significativos no sentido de reduzir o tempo de permanência de bebês nos abrigos e promover melhores condições de cuidado nesses ambientes.
Assim como, por força da lei, cresce a preparação dos candidatos à adoção de crianças acima dos dois anos que se encontram abrigadas, discutindo com eles aspectos sociais e psicológicos que envolvem essa experiência afetiva. Isso porque, como se procurou mostrar, a criança com histórico de institucionalização precoce e prolongada em geral acumula interrupções experimentadas nos relacionamentos com figuras de apego primárias na família, na instituição e acumula expectativas de que, no lar adotivo, o desfecho dessa relação possa ser diferente.

De qualquer modo, considera-se que os estudos aqui reportados servem como referência e estímulo para a realização de pesquisas semelhantes no Brasil, mas que possam apreender o máximo possível a complexidade que envolve o tema e as particularidades das experiências afetivas, reais e potenciais, nos contextos da institucionalização na infância e/ou das adoções consideradas tardias.

\section{Referências}

Ainsworth, M. D. S., Bell, S. M., \& Donelda, J. S. (1983). A ligação mãe-filho e o desenvolvimento social: A "socialização" como um produto da resposta recíproca a sinais. In M. P. M. Richards (Org.). A integração da criança no mundo social. Lisboa: Livros Horizonte. (Publicação original em 1974).

Ames, E. (1997). The development of romanian children adopted into Canada: Final report. Burnaby: Simon Fraser University; Funded by National Welfare Grants.

Beckett, C., Maughan, B., Rutter, M. Castle, J. Colvert, E., \& Groothues, C. (2006). Do the effects of early severe deprivation on cognition persist into early adolescence? From the english and romanian adoptees study. Child Development, 77(3), 696-711.

Bowlby, J. (1995). Cuidados maternos e saúde mental. (V. L. B. Souza e I. Rizzini, Trad.) São Paulo: M. Fontes. (Publicação original em 1976).

Bowlby, J. (1997). Formação e rompimento dos laços afetivos. (A. Cabral, Trad.). São Paulo: M. Fontes. (Publicação original em 1979).

Bretherton, I. (1992). The origins of attachment theory: John Bowlby and Mary Ainsworth. Developmental Psychology, 28, 759-775. 
Bronfenbrenner, U. (1996). A ecologia do desenvolvimento humano: Experimentos naturais e planejados. (M. A. V. Veronese, Trad.). Porto Alegre: Artes Médicas. (Publicação original em 1994).

Cicchetti, D., \& Barnett, D. (1991). Toward the development of the a scientific nosology of children maltreatment. In W. M. Grove \& D. Cichetti (Ed.). Thinking clearly about psychology: Personality and psychopatology (pp. 346-377). Minneapolis: University of Minnesota Press.

Chisholm, K. (1998). A three years follow-up of attachment and indiscriminate friendliness in children adopted from Romanian orphanages. Child Development, 69(4), 1092-1106.

Dozier, M., Stovall, K. C., Albus, K. E., \& Bates, B. J. M. (2001). Attachment for infants in foster care: the role of caregiver state mind. Child Development, 72(5), 1467-1477.

Freud, A., \& Burlingham, D. (1960). Meninos sem lar. Rio de Janeiro: Fundo de Cultura.

Fundo das Nações Unidas para a Infância - Unicef. (2010). Situação mundial da infância: Infância ameaçada. (B\&C Revisão de Textos, SP, Trad.). Brasília: Autor.

Hrdy, S. B. (2001). Mãe natureza: Uma visão feminina da evolução. Maternidade, filhos e seleção natural. (A. Cabral, Trad.). Rio de Janeiro: Campus. (Publicação original em 1999).

Instituto de Pesquisa Econômica Aplicada - Ipea. (2004). Levantamento nacional de abrigos para crianças e adolescentes da rede SAC. Recuperado em 2 jul. 2005, em www.url: http://.www.ipea.gov.br
O'Connor, T. G., Rutter, M., Beckett, C., Keaveney, L., \& Kreppner, J. M. (2000). The effects of global severe privation on cognitive competence: Extension and longitudianal follow-up. English and Romanian Adoptees Study Team. Child Development, 71(2): 376-390.

Provence, S., \& Lipton, R. C. (1962). Infants in instituciones. New York: International Universities Press, 1962.

Roy, P., Rutter, M., \& Pickles, A. (2000). Institutional care: Risk from family background or pattern of rearing? Journal of Child Psychology and Psychiatry, 41(2), 139-149.

Sigal, J., Perry, J. C., Rossignol, M. I., \& Ouimet, M. C. (2003). Unwanted infants: Psychological and physical consequences of inadeuate orphanage care 50 years later. American Journal of Orthopsychiatry, 73(1), 3-12.

Spitz, R. A. (1998). 0 primeiro ano de vida. (E. M. Rocha, Trad.). São Paulo: M. Fontes. (Publicação original em 1965).

Tizard, B., \& Hodges, J. (1978). The effects of early institutional rearing on the development of eight years old children. Journal Child Psychology and Psychiatry, 19(2), 99-118.

Zeanah, H. C., Nelson, C. A., Fox, N. A., Smyke, A. T., Marshall, P., Parker, S. W., et al. (2003). Designing research to study the effects of institutionalization on brain and behavioral development: The Bucharest Early Intervention Project. Development and Psychopathology, 15(4), 885-907.

Zeanah, H. C., Smyke, A. T., Koga, S., \& Carlson, E. (2005). Attachment in Institutionalized and Community in Romania. Child Development, 76(5), 1015-1028. 
